\title{
The Effect of Music on Preventing Intraoperative Awareness in Pediatric Patients Undergoing Open-Heart Surgery
}

\author{
Ghada Shalaby Khalaf Mahran, Nadia Taha Mohammed, Mona Aly Mohammed, Mervat Anwar Abd-Aziz \\ \& Sayed Kaoud Abd Elshafy.
}

Assistant lecturer of Critical Care Nursing Department, Faculty of Nursing, Assuit University, Egypt.

Professor of Critical care and Emergency Nursing Department, faculty of Nursing, Alexandria University, Egypt. lecturer of critical care nursing department, Faculty of Nursing, Assuit University, Egypt .

Assistant Professor of Anesthesia And Intensive Care Department, Faculty of Medicine, Assuit University, Egypt.

\begin{abstract}
Use of music has the potential to positively affect patient perception during intraoperative of surgical treatment. Intraoperative awareness is the most frustrating complication in patient undergoing surgery under general anesthesia. Study Design was Quasi-experimental research design. Three tools were used to conduct this study namily: "Preoperative assessment tool", "intraoperative assessment tool" and "postoperative assessment tool". Method: In a prospective, randomized double blind study, patients were randomized into two equal groups; In C group $(n=25)$ patients acted as the control and did not listening to music, while in music group $(n=25)$ patients listening to music. In both groups, auditory evoked potentials index electrodes connected before induction of anesthesia at operative room to detect depth of anesthesia and occurrence of intraoperative awareness. An interview with the patients and their parents to evaluate occurrence of awareness by using a semi-structured in-depth questionnaire. The main results: The results of the current study revealed that there was statistically significant decrease in occurrence of awareness in music group versus the control group ( $\mathrm{P}$ value $=0.000^{* * *}$ ). Conclusion: The application of music was highly effective in reducing intraoperative awareness.
\end{abstract}

Key words: Intraoperative Awareness, Music Therapy \& General Anesthesia.

\section{Introduction}

Intraoperative awareness with explicit recall is a complication of general anesthesia that is concerning to patients, anesthesia providers, and the general public. Intraoperative awareness refers to a patient's explicit recall of events during a procedure performed under general anesthesia .It is frequently leading to acute post traumatic stress disorder (Michapel 2011\& Michael 2013).

The incidence of intraoperative awareness was reported as approximately $0.1-0.2 \%$. Higher incidence of awareness (0.8-1.2\%) among children than has been reported in adult (Chen et al., 2011). The incidence of anesthesia awareness is higher for certain types of surgeries. Descriptive studies and case reports have revealed an incidence of 1.1 to 23 $\%$ in surgeries where cardiopulmonary bypass is used (Lekprasert et al., 2008 \& Nunes et al., 2012).

Intraoperative awareness cannot be measured during the intraoperative phase of general anesthesia, because the recall component of awareness can only be determined postoperatively by obtaining information directly from the patient. Hearing of voices seems to be the most commonly reported experience during awareness, reported in $30-89 \%$ of the awareness cases. Tactile perceptions have been described in $25-72 \%$, and paralysis or sensation of weakness in $17-85 \%$ of cases. Fear of future anesthetics was reported in $20 \%$ of patients and daytime anxiety in $17 \%$. Moreover, awareness may lead to late psychological symptoms, which may lead to a severe and debilitating illness (posttraumatic stress disorder) (Ghoneim et al., 2009 \& Wennervirta 2010).

Evidence-based use of music interventions are increasingly used before, during, and after surgical procedures to address a number of patient outcomes. In particular, the use of music as a nonpharmacological intervention to alleviate pain and anxiety is frequently cited in the literature. Current theory suggests that music functions as a distractor, diverting attention away from a negative catalyst and focusing awareness on soothing stimuli. Other tenets suggest that music activates the brain circuitry involved in reward processes, promoting an endorphin-like response. Finally, neuroscience suggests that music creates changes in neural pathways at the level of the cerebral cortex, hypothalamus, limbic system, and insula, which may induce relaxation and produce physiological changes (Gooding et al., 2012)

An increasing body of evidence suggests that awareness and learning occurs during general anaesthesia. Studies have shown that patients can respond favourably to taped intra-operative therapeutic suggestions as music, and exhibit a positive postoperative outcome such as reduction in 
pain, nausea and vomiting a better perception of well being and absence of fatigue (Jayaraman et al., 2006).

Springer (2006), recommended that nurses assess all patients for awareness postoperatively by eliciting information regarding the last memory before anesthesia and first memories when awakening. The most used employed assessment instrument for intraoperative awareness is the structured interview. It should be performed as an ongoing process for all patients including children because the nature of awareness involves memory which may gradually emerge over time (Ghoneim 2007 \& Errando et al., 2008).

A questionnaire or a structured interview is recommended in order to obtain a detailed account of the patient's experience.The first interview will be performed in the postanesthesia care unit or day surgery unit prior to discharge or transfer from that unit. In patients transferred from the operating room to the intensive care unit, the interview may occur in that unit upon satisfactory recovery from anesthesia and/or critical illness. A second interview should occur within 1-7 days following the general anesthetic and the third interview at day 30 ( Snedy, 2008).

\section{Significant of the study}

Awareness during general anesthesia is potentially an important issue for adults, infants and young children. It increased during young age and during cardiac surgery, yet it is considered to be a serious anaesthetic event .Being conscious during surgery is a traumatic event. The psychological ramifications of awareness can be severe, with up to $70 \%$ of patients displaying the criteria for post-traumatic stress disorder postoperatively (Thiele et al., 2013). Assuit pediatric hospital records indicated 96 cases for openheart surgery during the year of 2011.

\section{Aim of the study}

The aim of the current study is to investigate the effect of music listening on occurrence of intraoperative awareness in pediatric patients undergoing open-heart surgery.

\section{Subject and methods}

\section{Research design}

Quasi-experimental research design was utilized in this study.

Setting of the study

The study was conducted in operating room of pediatric open-heart surgery and pediatric post- operative cardiac ICU at Assuit pediatric University Hospital from (1 / 5 / 2012- 1 /5 /2014).

\section{Sample}

Convenient sample of 50 pediatric patients undergoing open-heart surgery with age 4 to 12 years old. This sample was assigned randomly into two groups:

- Control group (routine hospital care)

-Music listening group

Patients were randomly allocated into two equal groups using computer generated random numbers which were contained in a sealed envelope .

\section{Criteria of the sample}

\section{Exclusion criteria}

1. Previous cardiac surgery.

2. Hearing impairment.

3. Psychiatric or neurological illness.

4. History of drug use as corticosteroid treatment. Hypothesis

There will be a significant decrease in the incidence of intraoperative awareness in children undergoing open-heart surgery in music group than control group.

\section{Instrumentation and tools}

Three tools were used in this study to investigate the effect of music listening on intraoperative awareness and stress response in children undergoing open-heart surgery. These tools were developed and used by the researcher after reviewing the related literatures (Pfister 2011 \& Nunes et al., 2012). The instruments were tested for the content validity by selected juries of six critical care medical and nursing professionals (three critical care medical professionals and three critical care-nursing professionals) to assess adequacy of items of the tools. Reliability was assessed by Cronbach's Alpha and reliability level was $82 \%$ to assess the consistency and stability of the tools. A pilot study of nine patients was carried out in order to assess the clarity and applicability of the tools.

Tool one: "Preoperative assessment tool"

This tool was developed by the researcher after review of literatures (Nunes et al., 2012), to assess the patient during preoperative period to form base line data. This tool compromised four parts:

Part I:- Assessment of the sociodemographic patient's profile that included :patient's name ,sex ,age, weight and height.

Part II: Assessment of the patient's clinical data, which included 
A- medical diagnosis

B- American society of anesthesiology physical status classification that included the following:

(I): Healthy person (has no systemic disease).

(II): Mild systemic disease (can survive without operation).

(III): patient with severe systemic disease (will affect other system).

(IV): patient with severe systemic disease that is a constant threat to life.

(V): Moribund patient who is not expected to survive without the operation.

(VI): declared brain-dead patient whose organs are being removed for donor purposes.

Part (III) : Assessment of vital signs which included temperature, heart rate, respiration, systolic and diastolic blood pressure and mean arterial blood pressure (one measurement immediately before operation) .

Part (IV) : Assessment of type of music that the child prefers, tone and intensity.

Tool two: "Intraoperative assessment tool"

This tool was developed by the researcher after review of literatures (Nunes et al., 2012), to assess the patient during intraoperative period and comprised of two parts:

Part (I): Assessment of Patient's vital signs (three times : 1. at sternotomy ,2. after 10 minutes of connection to cardio-pulmonary bypass machine and 3. during rewarming).

Part (II) : assessment of depth of anesthesia and occurrence of intraoperative awareness by using auditory evoked potentials index (A line autoregressive index)

Tool three: "Postoperative assessment tool"

This tool was developed by the researcher after review of literatures (Sessler et al., 2002 \& Oliveira et al., 2014 ), to assess the patient during postoperative period and comprised of three parts:

Part (I) : Assessment of vital signs (two measurements: immediately at arrival at ICU and immediately after extubation).

Part (II) : Assessment of duration of mechanical ventilation and length of ICU stay.

Part (III) : A semi-structured in-depth interview (Nunes et al., 2012), to assess recall of intraoperative awareness in children .

\section{Methods}

Permission and informed concent to conduct the study was obtained from the hospital responsible authorities in the pediatric cardiothoracic operative room and postoperative intensive care unit as well as parents of the patients to carry out this study after explanation of the aim of the study.
The study followed common ethical principles in clinical research and was approved by the local ethics committee.

\section{Procedures and data collection}

The data were collected by the researcher through four phases:

A)Preoperative assessment phase

B) Intraoperative phase

C) postoperative phase

D) Evaluation phase

Patients were randomly assigned into two groups (control group and music listening group).

\section{For the control group}

The researcher assessed and observed the patients who were receiving the routine hospital nursing care during the three phases of data collection.

\section{A)Preoperative assessment phase}

\section{For all the groups}

A researcher interviewed with the patients and their parents at the night immediately before operation; they collected the questionnaire regarding sociodemographic and clinical data.

In the morning of the operation, the researcher measured vital signs to form base line data, check anesthetic machine, infusion pumps, adequacy of fresh gas flow, and appropriate placement and functioning of intravenous cannula, recorded medication used during induction and maintenance of anesthesia and labeled all medications as they are prepared and read the label prior to administration to prevent drug error.

\section{For Music listening group}

The researcher interviewed with the patients to ask about the most popular song or music that the child love, tone and intensity of music .The researcher recorded it to be used during intraoperative and postoperative period until extubation.

\section{B) Intraoperative phase}

A second researcher open the closed envelop in the morning before operation to know the group randomization (control or music group ).

The standard anesthetic technique was used in the form of anesthetic induction with sevoflurane plus fentanyl $5 \mathrm{megkg}^{-1}$ and cisatracurium $0.1 \mathrm{mgkg}^{-1}$ and maintained with sevoflurane, fentanyl $1 \mathrm{megkg}^{-1} \mathrm{~h}^{-1}$ and cisatracurium $0.05 \mathrm{mgkg}^{-1}$.

The researcher assessed and recorded vital signs (three measurements: at sternotomy, after 10 minutes of cross clamping and during rewarming).

In both groups auditory evoked potentials index (autoregressive line index) electrodes connected before induction of anesthesia at operative room until extubation at postoperative ICU to detect depth of anesthesia and occurrence of intraoperative awareness. 
The three silver/silver chloride electrodes were positioned at the mid-forehead; left forehead and mastoid. Earphones connected to the device, provide the auditory stimulus, an intermittent click. Processing time for AAI is 30 second for the first signal with a total update delay of 6 second.

\section{For Music listening group}

The researcher connected the patients with the recorded music via earphones connected to (MP4) from the immediate period before induction until extubation from mechanical ventilation at ICU.

\section{For control group}

The researcher did not connect any thing in the patients' ears during intraoperative and postoperative period until extubation.

\section{C)Postoperative phase}

In the immediate postoperative period, the researcher assessed vital signs (two measurements: immediately at arrival at ICU and immediately after extubation).

The researcher assessed and recorded duration of mechanical ventilation.

\section{For Music listening group}

The researcher connected the patients with the recorded music via earphones connected to (MP4) during postoperative period until extubation.

\section{D) The evaluation phase}

The researcher interviewed with the patients and their mothers to evaluate occurrence of awareness by using a semi-structured in-depth questionnaire. The interviews conducted on three occasions: within $24 \mathrm{~h}$ after operation, between 24 and $72 \mathrm{~h}$, and again at day 30.

\section{Results}

Section one: Pre-operative assessment sheet.

Table (1): Frequency distribution of patients regarding sociodemographic characteristics and clinical data.

\begin{tabular}{|c|c|c|c|}
\hline Items & Control group & Music group & P value \\
\hline Age range:((4-12years) & $7.48 \pm 2.48$ & $7.02 \pm 2.70$ & 0.534 \\
\hline $\begin{array}{l}\text { Sex:- Female } \\
\text {-Male }\end{array}$ & $\begin{array}{l}9(36 \%) \\
16(64 \%)\end{array}$ & $\begin{array}{l}10(40 \%) \\
15(60 \%)\end{array}$ & 0.771 \\
\hline Diagnosis :- atrial septal defect & $8(32 \%)$ & $7(28 \%)$ & \multirow{5}{*}{0.722} \\
\hline Ventricular septal defect & $6(24 \%)$ & $9(36 \%)$ & \\
\hline fallout's of tetralogy & $7(28 \%)$ & $6(24 \%)$ & \\
\hline Sub aortic membrane & $1(4 \%)$ & $2(8 \%)$ & \\
\hline valve replacement & $3(12 \%)$ & $1(4 \%)$ & \\
\hline $\begin{array}{l}\text { American society of anesthesiology physical } \\
\text { status of the patients :- Mild systemic disease }\end{array}$ & $23(92 \%)$ & $23(92 \%)$ & \multirow[t]{2}{*}{1.000} \\
\hline -patient with severe systemic disease & $2(8 \%)$ & $2(8 \%)$ & \\
\hline
\end{tabular}

NS There is no significant difference p. value $>0.05$

* Significant difference at $p$. value $<0.05$

Table (2): Comparison between the study groups related to vital signs and $\mathrm{SPO}_{2}$ at the immediate preoperative period, at sternotomy, at cross clamping, at rewarming at immediate ICU admission and at extubation.

\begin{tabular}{|c|c|c|c|c|}
\hline \multicolumn{2}{|c|}{ vital signs and SPO2 } & Control group & Music group & P value \\
\hline \multirow{5}{*}{ Temperature } & preoperative & $36.62 \pm .467$ & $36.26 \pm .617$ & $0.024 *$ \\
\cline { 2 - 5 } & At sternotomy & $35.71 \pm .68$ & $35.67 \pm .74$ & 0.844 \\
\cline { 2 - 6 } & At cross clamping & $30.84 \pm 2.14$ & $30.49 \pm 2.82$ & 0.626 \\
\cline { 2 - 6 } & At rewarming & $35.52 \pm 1.70$ & $35.72 \pm 1.35$ & 0.655 \\
\cline { 2 - 6 } & Immediate postoperative & $35.90 \pm .76$ & $36.04 \pm .88$ & 0.553 \\
\cline { 2 - 6 } & At extubation & $36.06 \pm 1.04$ & $36.6 \pm .70$ & $0.039 *$ \\
\hline \multirow{5}{*}{ Heart rate } & preoperative & $112 \pm 14.39$ & $106.44 \pm 14.21$ & 0.176 \\
\cline { 2 - 6 } & At sternotomy & $116.04 \pm 16.18$ & $111.44 \pm 21.89$ & 0.402 \\
\cline { 2 - 6 } & At rewarming & $129.20 \pm 22.36$ & $133.12 \pm 31.82$ & 0.617 \\
\cline { 2 - 6 } & Immediate post operative & $136.56 \pm 17.86$ & $136.12 \pm 14.24$ & 0.924 \\
\cline { 2 - 6 } & At extubation & $145.16 \pm 15.71$ & $140.12 \pm 17.90$ & 0.295 \\
\hline
\end{tabular}




\begin{tabular}{|c|c|c|c|c|}
\hline \multicolumn{2}{|c|}{ vital signs and SPO2 } & \multirow{2}{*}{$\begin{array}{c}\text { Control group } \\
19.76 \pm 4.437\end{array}$} & \multirow{2}{*}{$\begin{array}{c}\text { Music group } \\
19.04 \pm 5.231\end{array}$} & \multirow{2}{*}{$\frac{\text { P value }}{0.602}$} \\
\hline \multirow{5}{*}{ respiration } & preoperative & & & \\
\hline & At sternotomy & $22.80 \pm 13.05$ & $22.96 \pm 7.46$ & 0.958 \\
\hline & At rewarming & $20.44 \pm 7.81$ & $19.28 \pm 4.64$ & 0.526 \\
\hline & Immediate post operative & $22.48 \pm 6.41$ & $22.68 \pm 9.36$ & 0.930 \\
\hline & At extubation & $30.28 \pm 10.81$ & $31.80 \pm 9.72$ & 0.604 \\
\hline \multirow{5}{*}{ Mean blood pressure } & preoperative & $79.04 \pm 12.581$ & $75 \pm 11.35$ & 0.239 \\
\hline & At sternotomy & $78.88 \pm 16.84$ & $77.76 \pm 12.16$ & 0.789 \\
\hline & At rewarming & $57.96 \pm 9.12$ & $56.96 \pm 11.34$ & 0.733 \\
\hline & Immediate post operative & $66.44 \pm 14.43$ & $71.2 \pm 12.82$ & 0.224 \\
\hline & At extubation & $84.04 \pm 16.87$ & $83.28 \pm 18.58$ & 0.880 \\
\hline \multirow{5}{*}{$\mathrm{SPO} 2$} & preoperative & $96.67 \pm 7.04$ & $95.39 \pm 9.95$ & 0.602 \\
\hline & At sternotomy & $99.32 \pm 2.49$ & $98.60 \pm 3.32$ & 0.391 \\
\hline & At rewarming & $97.41 \pm 10.52$ & $98.95 \pm 2.60$ & 0.481 \\
\hline & Immediate post operative & $98.47 \pm 4.05$ & $99.92 \pm .4$ & 0.082 \\
\hline & At extubation & $98.54 \pm 2.82$ & $98.50 \pm 3.22$ & 0.970 \\
\hline
\end{tabular}

${ }^{N S}$ There is no significant difference

* Significant difference at p. value $<0.05$

Table (3): Distribution of patients regarding preference of music type and music tone in the music group.

\begin{tabular}{|c|c|c|}
\hline \multicolumn{1}{|c|}{ Assessment of music } & N & \% \\
\hline $\begin{array}{c}\text { Music type } \\
\text { Soft }\end{array}$ & 14 & 56.0 \\
\hline Classic & 3 & 12.0 \\
\hline New age & 8 & 32.0 \\
\hline $\begin{array}{c}\text { Music tone } \\
\text { Loud }\end{array}$ & 6 & 24.0 \\
\hline Low & 19 & 76.0 \\
\hline
\end{tabular}

Section two: intra- operative assessment sheet.

Table (4): The frequency distribution of auditory evoked potential level ( at sternotomy ,cross clamping and rewarming ).

\begin{tabular}{|c|c|c|c|c|c|}
\hline \multirow{2}{*}{ Items } & \multicolumn{2}{|c|}{ Control group } & \multicolumn{2}{|c|}{ Music group } & \multirow{2}{*}{$P$ value } \\
\hline & $\mathbf{N}$ & $\%$ & $\mathbf{N}$ & $\%$ & \\
\hline $\begin{array}{l}\text { Auditory evoked potential at sternotomy-Deep } \\
\text { anesthesia }\end{array}$ & 1 & 4.0 & 1 & 4.0 & \multirow{4}{*}{0.744} \\
\hline general anesthesia & 12 & 48.0 & 13 & 52.0 & \\
\hline Light anesthesia & 10 & 40.0 & 7 & 28.0 & \\
\hline Awake & 2 & 8.0 & 4 & 16.0 & \\
\hline $\begin{array}{l}\text { Auditory evoked potential at cross clamping- } \\
\text { Deep anesthesia }\end{array}$ & 4 & 16.0 & 7 & 28.0 & \multirow{4}{*}{0.148} \\
\hline general anesthesia & 7 & 28.0 & 12 & 48.0 & \\
\hline Light anesthesia & 12 & 48.0 & 5 & 20.0 & \\
\hline Awake & 2 & 8.0 & 1 & 4.0 & \\
\hline $\begin{array}{l}\text { Auditory evoked potential at rewarming: Deep } \\
\text { anesthesia }\end{array}$ & 0 & 0.0 & 4 & 16.0 & \multirow{4}{*}{$0.007 * *$} \\
\hline general anesthesia & 5 & 20.0 & 12 & 48.0 & \\
\hline Light anesthesia & 11 & 44.0 & 7 & 28.0 & \\
\hline Awake & 9 & 36.0 & 2 & 8.0 & \\
\hline
\end{tabular}

-NS There is no significant difference

- * Significant difference at p. value $<0.05$ 
Section three: Postoperative assessment sheet

Table (5): Duration of mechanical ventilation and length of ICU stay during post-operative period.

\begin{tabular}{|l|c|c|c|}
\hline \multicolumn{1}{|c|}{ Items } & Control group & Music group & P value \\
\hline $\begin{array}{l}\text { Duration of mechanical ventilation } \\
\text {-duration less than 60 minute }\end{array}$ & $13(52 \%)$ & $17(68 \%)$ & \\
\cline { 1 - 2 } -duration: 60-120 minute & $8(32 \%)$ & $6(24 \%)$ & \multirow{2}{*}{0.568} \\
\hline -duration : 120-180 minute & $3(12 \%)$ & $2(8 \%)$ & \\
\hline -more than 180 minute & $1(4 \%)$ & 0 & 0.672 \\
\hline Length of ICU stay in days & $4.68 \pm 1.107$ & $4.84 \pm 1.51$ & \\
\hline
\end{tabular}

- NS There is no significant difference $\quad$ * Significant difference at $p$. value $<0.5$

ICU: intensive care unit

Table (6): The frequency distribution of type, sensation and episodes of awareness and time of patient's report.

\begin{tabular}{|c|c|c|c|c|c|c|}
\hline & \multirow{3}{*}{ Items } & \multicolumn{4}{|c|}{ Group } & \multirow{3}{*}{$\begin{array}{c}\mathbf{P} \text { value } \\
\mathbf{P}_{1}\end{array}$} \\
\hline & & \multicolumn{2}{|c|}{ Control group } & \multicolumn{2}{|c|}{ Music group } & \\
\hline & & $\mathrm{N}$ & $\%$ & $\mathrm{~N}$ & $\%$ & \\
\hline \multirow{2}{*}{ Feeling of awareness } & No & 6 & 24.0 & 19 & 76.0 & \multirow[b]{2}{*}{$0.000 * * *$} \\
\hline & Yes & 19 & 76.0 & 6 & 24.0 & \\
\hline \multirow{2}{*}{ Type of awareness } & Possible & 7 & 28.0 & 3 & 12.0 & \multirow[b]{2}{*}{$0.001 * *$} \\
\hline & definite & 12 & 48.0 & 3 & 12.0 & \\
\hline \multirow{3}{*}{ Sensation of awareness } & tactile & 9 & 36.0 & 3 & 12.0 & \multirow{3}{*}{$0.002 * *$} \\
\hline & auditory & 7 & 28.0 & 3 & 12.0 & \\
\hline & Tactile and auditory & 3 & 12.0 & 0 & 0.0 & \\
\hline \multirow{3}{*}{ Episodes of awareness } & Heard noise. & 7 & 28.0 & 3 & 12.0 & \multirow{3}{*}{$0.002 * *$} \\
\hline & $\begin{array}{l}\text { Heard noise and felt with } \\
\text { endotracheal tube but tried to } \\
\text { move and communicate but } \\
\text { could not. }\end{array}$ & 3 & 12.0 & 0 & 0.0 & \\
\hline & $\begin{array}{l}\text { tried to open eye, move and } \\
\text { communicate but could not } \\
\text { but felt with endotracheal } \\
\text { tube }\end{array}$ & 9 & 36.0 & 3 & 12.0 & \\
\hline \multirow{3}{*}{ Time of report } & Day of surgery & 10 & 40.0 & 3 & 12.0 & \multirow{3}{*}{$0.007 * *$} \\
\hline & 1-4 days after surgery & 6 & 24.0 & 2 & 8.0 & \\
\hline & At day 30 after surgery & 9 & 36.0 & 20 & 80.0 & \\
\hline
\end{tabular}

${ }^{N S}$ There is no significant difference $\quad *$ Significant difference at $p$. value $<0.05$

Table (1): Showed that: As regard to patient's age, it was noticed that there was no statistically significant difference between both groups $(\mathrm{P}>0.05)$. As regard to patient's sex, it was noticed that a highly percent of patients in both groups were male patients and there was no statistically significant difference between both groups (P> 0.05). Regarding to medical diagnosis, results revealed a relatively high percent of patients in the music group, were having ventricular septal defect (VSD) and there was no statistically significant difference between both groups $(\mathrm{P}>0.05)$. Regarding to American society of anesthesiology physical status of the patients (ASA), results revealed that the majority of patients were class II (mild systemic disease) in the control and music and there was no statistically significant between all the study groups $(\mathrm{P}>0.05)$.

Table (2) showed that: Regarding temperature at the immediate preoperative period and at extubation, results revealed that there was a statistically significant difference between the control and music group $\left(\mathrm{P}\right.$ value $=0.024^{*} \& \mathrm{P}$ value $\left.=0.039 *\right)$. Regarding respiration, heart rate, diastolic blood pressure, mean blood pressure and $\mathrm{SPO}_{2}$, it was noticed that there was no statistically significant difference between both groups $(\mathrm{P}>0.05)$. Regarding systolic blood pressure at extubation, results revealed that there was statistically significant difference 
between the control and music group (P value $=0.04 *)$.

Table (3): showed that: most of patients $(56 \%$ and $76 \%$ ) prefer soft music type and low music tone respectively.

Table (4): Regarding to auditory evoked potential at sternotomy, showed that a high percent of patients were under general anesthesia in the control and music and there was no statistically significant difference between all the study groups ( $\mathrm{P}$ value $>$ 0.05). Regarding to auditory evoked potential at cross clamping and rewarming, results revealed a high percent of patients were under light anesthesia in the control group, while in the music group; high percent of patients were under general anesthesia, with high statistically significant difference when comparing control group with music (P value $=0.007 * *)$.

Table (5): Regarding to duration of mechanical ventilation during post -operative period, showed that the majority of patients were connected to mechanical ventilation less than 60 minutes in control and music groups . As regard to length of ICU stay, it was found that cases stayed fewer days in music group in comparison with control group but without statistically significant difference ( $\mathrm{P}$ value $>0.05$ ) .

Table (6): Regarding to feeling of awareness, showed that there was statistically significant difference when comparing music group versus the control group $(\mathrm{P}$ value $=0.000 * * *)$. Regarding to type of awareness, results revealed that high percent of patients were definite awareness and there was statistically significant difference when comparing music group versus the control group ( $\mathrm{P}$ value $=0.001 * * *)$. Regarding to sensation of awareness, results revealed that high percent of awareness was auditory sensation and there was statistically significant difference when comparing music group versus the control group ( $\mathrm{P}$ value $=0.002 * * *)$. Regarding to episodes of awareness, results revealed that the highest percent of patients heard noise. Regarding to time of patient's report, results revealed that high percent of patients reported episodes of awareness in the first day of surgery.

\section{Discussion}

Therapeutic sounds has been associated with positive results in some adults during surgery, but it is unknown how therapeutic sounds affect children (Martin, et al., 2014), Hence, the present study aims to investigate the effect of music listening on intraoperative awareness in children undergoing open-heart surgery.

Regarding to effect of listening music on occurrence of awareness, results revealed that there was statistically significant decrease on occurrence of awareness in music group versus control group. The results of the current study concluded that the activation of auditory pathway by music during surgery inhibits the central transmission of nociceptive stimuli and increase patient's relaxation. This result was in line with (Jayaraman, et al., 2006) who mentioned that music as the senses deviation acts like a mask on the annoying sounds of the operation and leads to reduction of stress and anxiety and reduction of narcotic drugs consumption. Regarding to the patient's age of the study sample, the finding of the current study revealed that, age of the studied patients ranged from 4 to 12 years old. The current study explained that clearly explicit recall could not be used as a measure of awareness in very young children, while in older children the developmental changes in explicit memory need to be considered when measuring or defining an episode of explicit recall, so the age of allsample were notless than 4 years old. This result was in line with (Davidson, 2005) who included children with age 512 years in his study. He explained that children begin to develop some form of explicit memory at around 3 years of age. Between this age and adulthood, explicit memory continues to be refined and developed.

Regarding to patients' diagnosis, the finding of the current study revealed that the most common diagnosis was atrial septal defect and ventricular septal defect, but less common cases were tetralogy of fallouts and sub aortic membrane. This result was in line with (Hoffman, 2010) who reported that the majority of patients in his study were atrial \& ventricular septal defect..

The finding of the current study revealed that regarding to American society of anesthesiology physical status (ASA) classification, the majority of patients were with mild systemic disease (class II) and less number of patients were patient with severe systemic disease (class III-V ) . The current study indicated that, less cases of the study sample were having tetralogy of fallouts .Moreover; these patients were American society of anesthesiology physical status (ASA class III) and this take longer duration of operation, which increased the risk of intraoperative awareness and other intraoperative complication. These results were in line with (Davidson, 2011) that indicated that $93.9 \%$ of cases were ASA I and II but only $6.1 \%$ were ASA III and IV. As regard the patient's sex among the study sample, the finding of the current study revealed that the majority of the study sample was male and less percent were female This result was in line with (Oud-Alblas, et al., 2009), who indicated that male were ( $54.6 \%$ ) while female were $(45.3 \%)$. 
Regarding to sensation of awareness, results revealed that highly percent of awareness was auditory sensation. Regarding to episodes of awareness, the current results revealed that the highest percent of patients heard noise. The results concluded that hearing is the last perception to be lost during anesthesia induction, and the first to be restored after recovery. Therefore, it was the most commonly reported form of intraoperative sensation. These results were in line with (Ziętkiewicz, 2012) who reported that hearing of voices seems to be the most commonly reported experience during awareness.

As regard the physiological assessment of vital signs, the results of the current study revealed that there was no statistically significant difference between both groups in the preoperative period. These results could be explained that all patient during preoperative period, not exposed to any intervention to produce significant difference to be observed. These results were in line with (Zengin, et al., 2013) and (Chalfin, et al., 2007) who indicated that a complete assessment of all system is performed to determine the postoperative status of the patient as compared with the preoperative base line and to note anticipated changes in the postoperative period

As regard to studying the effect of listening music on vital signs and $\mathrm{SPO}_{2}$ during intraoperative, the results of the current study revealed that there was no statistically significant difference between the groups. It could be explained that confounding variables such as medications interfering with vital signs, more specifically, muscle relaxant and opioid's medication which was maintained to a necessary level during surgery that suppress autonomic nervous system, so no statistically significant difference could be observed. These results were in contrast to (Sandstrom, \& Russo, 2010) who compared recorded music of four different tempi and moods, but only found a reduction in heart rate for peaceful, low tempo music.

As regard to studying the effect of listening music on vital signs at immediate postoperative and at extubation, it was found that there was no statistically significant difference between the control and music group. The results indicated that increased energy levels may be reflected in vital signs. These results was in contrast to (Nilsson, 2008 \& Suhartini 2011) who reported that significant effects of music interventions were documented in the reduction of heart rate, blood pressure, respiratory rate, and reduced blood cortisol levels.

Regarding to duration of mechanical ventilation during post -operative period, most of cases weaned rapidly within the first hour in music group, while this difference was not significant when compared control group with music group. This was in contrast to (Hunter, et al., 2010), who reported that music reduce weaning process from mechanical ventilation. Application of evidence based practice as music during surgery or any stressful invasive procedure has therapeutic effect on patients and family.it was proved that those intervention reduce occurrence of intraoperative awareness.

\section{Conclusion}

The present study highlighted the therapeutic effect of application of music therapy in preventing intraoperative awareness in children undergoing open-heart surgery.

Based on the results of this study, it could be concluded that

Music evokes desired feeling that serve as distraction from unpleasant stimuli. It can also elicit memories of life events or hold certain meanings that can elicit emotional responses, increase the release of endorphins and enkephalins and decrease circulating catecholamines.

\section{Recommendations}

Based on the findings of the current study, the following recommendations are suggested Emphasize the importance of using therapeutic sounds as music during intraoperative period for preventing intraoperative awareness and its complications.

Appropriate post operative follow up of all patients who have undergone general anesthesia, including children for assessment and detection of occurrence of intraoperative awareness.

\section{References}

1. American Association of Nurse Anesthetists. Anesthetic awareness. (C) Copyright (2010).

2. Errando C., Sigl J., Robles M., Calabuig E., García J., Arocas F., Higueras R., Del Rosario E., López D., Peiró C., Soriano J., Chaves S., Gil F., García-Aguado R., (2008): Awareness with recall during general anaesthesia: a prospective observational evaluation of 4001 patients. Br J Anaesth; 101,pages :178-85.

3. Ghoneim M., Block R., Haffarnan M., \& Mathews M., (2009): Awareness during anesthesia: risk factors, causes and sequelae: a review of reported cases in the literature. Anesth Analg; 108,pages: 527-35.

4. Ghoneim M., (2007): Incidence and risk factors for awareness during anaesthesia. Best Prac Res Clin Anaesthesiol;21,pages:327-43

5. Jayaraman L., Sharma S., Sethi N., Sood J., Kumra V., (2006): Does intraoperative music 
therapy or positive therapeutic suggestions during general anaesthesia affect the postoperative outcome? Adouble blind randomized trial .Indian J., Anaesth, 4, pages :258-261.

6. Lekprasert V., Elizabeth A., Frost M., \& Pausawasd S., (2008): Intraoperative Awareness ; major factor or non existent M., ANESTH; 19,No:6.

7. Michael S., Mashour G., Prevention of Intraoperative Awareness with Explicit Recall :Making Sense of the Evidence. Anesthesiology, (2013): 118,pages: 449-56.

8. Michael S., Jacobsohn E., Glick D., (2011): Prevention of intraoperative awareness in a highrisk surgical population. The new England journal of medicine; 365 , no: 7.

9. Nilsson U., (2008) : The Anxiety- and Pain Reducing Effects of Music Interventions: A Systematic Review. AORN JOURNAL; 87, 4,pages: 780-807.

10. Nunes R., Porto V., Miranda V., Andrade N., (2012): Risk Factors for Intraoperative Awareness. Rev Bras Anestesiol; 62,pages: 3: 365-374.

11. Sneyd J., and Mathews D., (2008): Memory and awareness during anaesthesia . British Journal of Anaesthesia; 100 ,6,pages: 742-4 .

12. Springer, R., (2006). Anesthesia awareness. Plastic Surgical Nursing, 26(2), pp. 96-97.

13. The Joint Commission (2012): Preventing and managing the impact of anesthesia awareness. Sentinel Event Alert;20, Issue 32. Available at http://

www.jointcommission.org/assets/1/18/SEA_32.P DF.

14. Wang E., songzongbin P., (2011): Incidence and risk factors of intraoperative awareness during general anesthesia. $\mathbf{J}$ cent south univer;3.,6,p.7.

15. Wennervirta J., (2010): Measurements of adequacy of anesthesia and level of consciousness during surgery and intensive care. ISBN 978-952-92-7152-8 (paperback) .ISBN 978-952-10-6180-6 (pdf)Yliopistopaino. Department of Anesthesiology and Intensive Care Medicine .Helsinki University Hospital .University of Helsinki .Finland 